\title{
BMJ Open Parents' Active Role and ENgagement in The review of their Stillbirth/perinatal death 2 (PARENTS 2) study: a mixed- methods study of implementation
}

\author{
Christy Burden (D) , 'Danya Bakhbakhi, ${ }^{1}$ Alexander Edward Heazell (1) , ${ }^{2}$ \\ Mary Lynch, ${ }^{1}$ Laura Timlin, ${ }^{1}$ Charlotte Bevan, ${ }^{3}$ Claire Storey, ${ }^{4}$ Jennifer J Kurinczuk, ${ }^{5}$ \\ Dimitrios Siassakos (i) $6,7,8,9$
}

\begin{abstract}
To cite: Burden C, Bakhbakhi D, Heazell AE, et al. Parents' Active Role and ENgagement in The review of their Stillbirth/ perinatal death 2 (PARENTS 2) study: a mixed-methods study of implementation. BMJ Open 2021;11:e044563. doi:10.1136/ bmjopen-2020-044563
\end{abstract}

- Prepublication history and additional materials for this paper is available online. To view these files, please visit the journal online (http://dx.doi org/10.1136/bmjopen-2020044563).

Received 14 September 2020 Revised 20 January 2021 Accepted 09 February 2021

Check for updates

(c) Author(s) (or their employer(s)) 2021. Re-use permitted under CC BY-NC. No commercial re-use. See rights and permissions. Published by BMJ.

For numbered affiliations see end of article.

Correspondence to

Dr Christy Burden;

christy.burden@bristol.ac.uk

\section{ABSTRACT}

Objective When a formal review of care takes places after the death of a baby, parents are largely unaware it takes place and are often not meaningfully involved in the review process. Parent engagement in the process is likely to be essential for a successful review and to improve patient safety. This study aimed to evaluate an intervention process of parental engagement in perinatal mortality review (PNMR) and to identify barriers and facilitators to its implementation.

Design Mixed-methods study of parents' engagement in PNMR.

Setting Single tertiary maternity unit in the UK. Participants Bereaved parents and healthcare professionals (HCPs).

Interventions Parent engagement in the PNMR (intervention) was based on principles derived through national consensus and qualitative research with parents, HCPs and stakeholders in the UK.

Outcomes Recruitment rates, bereaved parents and HCPs' perceptions.

Results Eighty-one per cent of bereaved parents approached (13/16) agreed to participate in the study. Two focus groups with bereaved parents $(n=11)$ and HCP $(n=7)$ were carried out postimplementation to investigate their perceptions of the process.

Overarching findings were improved dialogue and continuity of care with parents, and improvements in the PNMR process and patient safety. Bereaved parents agreed that engagement in the PNMR process was invaluable and helped them in their grieving. HCP perceived that parent involvement improved the review process and lessons learnt from the deaths; information to understand the impact of aspects of care on the baby's death were often only found in the parents' recollections.

Conclusions Parental engagement in the PNMR process is achievable and useful for parents and HCP alike, and critically can improve patient safety and future care for mothers and babies. To learn and prevent perinatal deaths effectively, all hospitals should give parents the option to engage with the review of their baby's death.
Strengths and limitations of this study

First study to investigate parent engagement in the review process after the death of a baby.

- Robust development of our intervention with parents/patients and stakeholders.

L Limited to a single maternity unit in the UK.

\section{INTRODUCTION}

Parents whose baby have died have the greatest stake in understanding why their baby died and what contributed to their baby's death. They can also offer unique insights into their care, yet there has been little formal study of engaging them in the review process after the death of their baby. In the last decade, enquiries into 'poor performing' maternity units have highlighted the need for more robust reviews after a perinatal death, as well as transparent engagement with bereaved parents and clarity on lessons learnt. ${ }^{1-3}$ A recent multinational online survey has shown that parents' engagement in the perinatal mortality review process is limited and inconsistent worldwide. ${ }^{4}$ Two Confidential Enquiries into Stillbirths in the UK identified that case reviews conducted by maternity units only included parents in 5\% and $7 \%$ of cases, respectively. ${ }^{4}$ Thus, those with the greatest stake in the outcome of the perinatal mortality review (PNMR) are rarely involved. ${ }^{5}$

The Learning from Deaths framework from NHS England highlights the importance of the involvement of families in investigations after any death in hospital, developed in response to previous poor experiences of families. ${ }^{6}$ After a perinatal death, parents, particularly mothers, have a unique and vital perspective on everything that happened to them and their baby, being the only people 
present for the entirety of the pregnancy. Parents place the highest value on information about the causes of and contributors to their baby's death. ${ }^{7}$ Involving parents in understanding the events they have experienced could therefore, potentially help in grieving by helping them process events around their baby's death, including addressing their own guilt and blame. This is supported theoretically by the Dual Process Model of Grief, which states that directly confronting grief can enable healthy coping mechanisms. ${ }^{8}$ Furthermore, improving the PNMR process with parent engagement may also result in improvements in patient safety, leading to cost savings for the National Health Service and society, as perinatal death has significant far-reaching psychological and socioeconomic effects including: depression, psychological morbidity in subsequent pregnancies and additional negative impact on society. ${ }^{9-11}$

Previous research from the Parents' Active Role and ENgagement in The review of their Stillbirth (PARENTS) portfolio of studies ${ }^{711-13}$ reported that bereaved parents and healthcare professionals (HCPs) both support the opportunity for parent engagement in the PNMR process. ${ }^{711}$ The majority of bereaved parents perceived that not being involved in the review could further exacerbate their distress and grief. ${ }^{7}$ Following this work, a national (UK) stakeholder consensus meeting was held to generate core recommendations and principles for parent engagement. ${ }^{13}$

In 2016, the Department of Health and Social Care (England), with Scotland and Wales, commissioned a national Perinatal Mortality Review Tool (PMRT) in the UK, to improve and standardise the quality of local hospital reviews when perinatal deaths occur, including recommending the engagement of parents. ${ }^{14}$ To facilitate this objective, this study aimed to evaluate a process for parent engagement using the recommendations developed by stakeholders. We aimed to investigate whether parent engagement in the PNMR was achievable and to identify barriers and facilitators to its implementation.

\section{METHODS}

The study methods for this pilot study were published in detail in the full Parents' Active Role and ENgagement in The review of their Stillbirth/perinatal death 2 (PARENTS 2) protocol. ${ }^{15}$ Methodology adhered to the COnsolidated criteria for REporting Qualitative research guidelines. ${ }^{16}$

\section{Patient and public involvement}

The views of parents with lived experience of perinatal loss were involved in developing, implementing and interpreting the study. Bereaved parents were co-applicants in the design of the study and grant application. Bereaved parents were integral to the design of the intervention at the National consensus meeting. Members of the study team and patient advisors were bereaved parents and were therefore involved in the study conduct and analysis.
A summary of the results will be disseminated to all study participants.

\section{Participant selection}

Inclusion criteria

Women and their partners were invited to participate in the study if they experienced a perinatal death in a tertiary maternity unit in the South West of the UK caring for approximately 6000 women each year from November 2018 to May 2019. Perinatal death included all stillbirths (birth of a baby with no signs of life after 24 weeks' completed gestation) and neonatal deaths (death of a baby within 4 weeks of birth).

\section{Intervention-engagement of bereaved parents in the PNMR}

The recruitment of parents and pathway for parent engagement in the PNMR process was developed using findings from the PARENTS 2 consensus study. ${ }^{13}$ The flow chart depicts the intervention-parent engagement in the PNMR (online supplemental file 1).

\section{Recruitment of bereaved parents}

The detailed recruitment process is published elsewhere. ${ }^{11}$ In brief, following a bereavement in the maternity or neonatal department the midwife or neonatal nurse caring for the parent/s explained the PNMR process and the opportunity for parental engagement. The parent/s were given a letter and a brief initial information leaflet about the study. An information pack was sent to parent/s wishing to participate using the communication method of their choice within 1 week after their baby died containing: a cover letter, a detailed information leaflet about the study, a sample consent form, a PNMR parent feedback form and a proposed date for the PNMR meeting. The exact PNMR parent feedback form was modified and developed from the national published consensus study (online supplemental file 2) ${ }^{13}$ Parent/s received a telephone call from the research team 1 week after the information pack had been sent to them and they subsequently received a home visit from the research midwife to gain formal written consent and obtain the parents' feedback.

\section{PNMR meeting}

The PNMR meeting took place after each perinatal death. All questions and comments received from parents via the feedback form were discussed and presented at the meeting. Obstetricians, midwives (hospital and community staff), neonatologists, pathologists and ultrasonographers were invited to attend.

\section{Feedback consultation}

Once the PNMR meeting had taken place, a further telephone call to the parent/s was made by a member of the research team to offer feedback from the PMNR by a face-to-face consultation, telephone or post. If this coincided with a planned consultant follow-up meeting, this would be undertaken at this consultation. A plain English summary (lay) was written to present the feedback and 
summarise the PNMR meeting. Parent/s at this point were asked if they would like to participate in a postintervention focus group to discuss their experiences of being engaged in the PNMR.

\section{Recruitment of HCP}

HCP (midwives, obstetricians, neonatologists, neonatology nurses) working in the department over the study period were emailed to ask if they would like to participate in a postintervention focus group to discuss their experiences of parents being engaged in the PNMR.

\section{Data collection}

Post intervention focus group discussions and feedback forms

The two focus group discussions (parents and HCP) took place in a meeting room away from the clinical environment. Focus group attendees were asked to provide written consent, including consent to be audio recorded and for anonymised quotes to be used in reporting. Researchers (the authors $\mathrm{CAB}, \mathrm{CB}$, DS and $\mathrm{DB}$ ) experienced in qualitative interviewing conducted the focus group discussions. $\mathrm{CBu}$ is a female Consultant Obstetrician/senior lecturer (MD), DS is a male Consultant Reader in Obstetrics (associate professor) (MD) and DB is a female Clinical Research Fellow in Obstetrics and Gynaecology. A research midwife and/or a research facilitator were also present to co-facilitate the focus groups and moderate group dynamics. Lay representatives $(\mathrm{CB}$-senior advisor at Stillbirth and Neonatal Death Charity and bereaved parent herself) co-facilitated the focus group discussion with parents to ensure they felt supported in voicing their opinion. The researchers followed the focus group schedules developed and piloted with the Project Advisory Board (online supplemental file 3). The researchers and research midwife all work clinically within the hospital trusts and therefore may already have a professional relationship with the participants. The participants were made aware of the goals of the research prior to commencing the interviews. Contemporaneous field notes were taken to provide the recorded discussions with context.

Feedback forms to ascertain parents' experiences and perspectives were given to all participants during the intervention process described.

\section{Data analysis}

The audio recordings of the focus group interviews were transcribed in full, stored and analysed using NVivo V.10 software. The focus group data were analysed using the inductive thematic analysis technique as described by Braun and Clark. ${ }^{17}$ The transcripts were also sent to participants to ensure participants perceived the transcripts reflected the discussions accurately. The transcripts were read and re-read, and coded independently by two independent researchers, while the wider members of the research team had the opportunity to read through each focus group transcript. Identified themes from the data were discussed with the research team. A coding tree was produced from the resulting themes and subthemes with supporting quotes identified. The same method of analysis ${ }^{17}$ was replicated and undertaken on the parental engagement feedback forms by two independent researchers $(\mathrm{CAB}, \mathrm{ML})$ to investigate recurrent themes in the parents' feedback.

\section{Sample size}

With an estimated perinatal death rate of about 1:200 and conservative estimates of recruitment rate of about $60 \%$ (unit has a track record of $>60 \%-70 \%$ recruitment of bereaved parents in research), we estimated to recruit a pragmatic sample of about 10-12 parent sets within the 6-month study period (7000-8000 births per annum: $2 \times 60 \% \times 1: 200$ ). We aimed to recruit all the parents who participated in the intervention pathway to the focus group. HCPs were purposively sampled from those engaged in the PNMR ( $\mathrm{n}=20)$ and recruited to maximise variation in profession and seniority (aiming for $n=5-8$ ).

\section{RESULTS}

Sixteen bereaved mothers were approached from November 2018 to May 2019; 13 mothers $(81 \%)$ agreed to participate in the study. Twelve mothers (75\%) approached had experienced a stillbirth and four $(25 \%)$ a neonatal death. The mean age of the mothers included in the study was 33 years (range 21-43) and 77\% (10/13) were of white ethnicity, and parity ranged from 1 to 10 . Mean gestation at time of birth/stillbirth was 34 weeks' gestation (range 24-41 weeks). Investigations revealed placental insufficiency in five deaths (38\%) and placental abruption in three deaths (23\%). Table 1 describes the characteristics of the participants in the intervention study. The three parents who declined

\begin{tabular}{|c|c|c|c|c|}
\hline Participants & SB/NND & PM & $\begin{array}{l}\text { Visit time } \\
\text { (min) }\end{array}$ & $\begin{array}{l}\text { Serious } \\
\text { untoward } \\
\text { incident }\end{array}$ \\
\hline 1 & SB & $\mathrm{Y}$ & 60 & $\mathrm{~N}$ \\
\hline 2 & SB & $\mathrm{N}$ & 45 & $\mathrm{~N}$ \\
\hline 3 & NND & $\mathrm{N}$ & 45 & $\mathrm{~N}$ \\
\hline 4 & SB & $\mathrm{N}$ & 45 & $\begin{array}{l}\mathrm{Y} \text { (trust } \\
\text { complaint) }\end{array}$ \\
\hline 5 & NND & $\mathrm{N}$ & 45 & $\mathrm{~N}$ \\
\hline 6 & SB & $\mathrm{Y}$ & 60 & $\mathrm{~N}$ \\
\hline 7 & SB & $\mathrm{N}$ & 75 & $\mathrm{~N}$ \\
\hline 8 & NND & $\mathrm{N}$ & 75 & $\mathrm{~N}$ \\
\hline 9 & SB & Y & 75 & $\mathrm{~N}$ \\
\hline 10 & SB & Y & 50 & $\mathrm{~N}$ \\
\hline 11 & SB & Y & 60 & $\mathrm{~N}$ \\
\hline 12 & SB & $\mathrm{N}$ & 60 & $\mathrm{~N}$ \\
\hline 13 & SB & $\mathrm{N}$ & 180 & $\begin{array}{l}\text { Y (trust } \\
\text { complaint) }\end{array}$ \\
\hline
\end{tabular}

NND, neonatal death; PM, Post-mortem; SB, stillbirth. 
to participate experienced a stillbirth between 35 and 37 weeks gestation; reasons stated were another bereavement in the family, no questions or no wish to participate. Median visit time by the research midwife to obtain feedback for the review was $60 \mathrm{~min}$ (range $45-180 \mathrm{~min}$ ). Median time from babies' death to home visit was 3 weeks and 2 days (range 3-9 weeks), median time from home visit to PNMR was 6 weeks and 2 days (range 3-11 weeks) and from babies' death to consultant follow-up meeting was 10 weeks and 2 days (range 8-29 weeks).

Two separate post-intervention focus groups took place in July 2019, one with bereaved parents (95 min) who had participated in the study and one with HCPs $(55 \mathrm{~min}$ ) working at the time of the implementation of the study for parent engagement in the PNMR. Eighteen participants were recruited to the two separate focus group discussions; 11 bereaved parents (mother- 7 and fathers-4) and 7 HCPs.

\section{Bereaved parents post-intervention focus group}

Three main themes were identified from the focus group with bereaved parents: better dialogue and continuity of care with parents, improvements to the perinatal mortality review process and enhanced patient safetymaking pregnancy safer (table 2, figure 1).

\section{Better dialogue and continuity of care with parents}

\section{We could ask?!}

Parents were positive about having the opportunity to talk and be listened to and to have their concerns and opinions heard. Even if they perceived there was no concrete conclusion or answer to their questions, it was still felt to be greatly beneficial to be able to comment, discuss and be listened to. Parents perceived that to not have their voice or questions included in the PNMR would have been distressing.

\section{Parent engagement not part of routine care}

One of the striking and unanimous findings was that all parents, having had the opportunity to contribute to the PNMR process, were surprised and dismayed that this (parent engagement in the review) was not part of standard care.

\section{Face-to-face-useful to be in home environment}

There were extremely positive perceptions of the home face-to-face visit undertaken in the study, that parents perceived would not be replicated if they were asked for feedback by letter, email or phone. Many parents commented that if they had been asked for feedback by any other modality than face-to-face it would be very impersonal at a very traumatic time and that they would have said no to engaging in the review.

\section{Understand first-to move on}

The majority of parents felt that being engaged in the review, being able to ask questions and get answers (where possible) made them able to understand better the events that they had experienced, which some parents perceived helped them in coming to terms with their loss.
Improvements to the PNMR process

\section{Right timing of providing feedback to the review}

Parents felt the schedule of letting them know about the review process in hospital and then seeking feedback was, for the majority, acceptable as it gave the right balance of enough time to gather their thoughts, but not too long from their baby's death so they did not feel engaged. However, participants identified that this may be different for each individual parent and that it was hard to get the exact timing right for all. Parents found it useful to be able to talk to someone and give feedback after they had left hospital.

\section{Key contact in the hospital was vital}

Parents perceived a key contact to provide continuity and guide them through the process of being engaged in the review was vital, reinforcing the key role of a bereavement team, and the need for a structure to be in place to implement parent engagement in the review effectively.

\section{Mixed perceptions of the feedback form}

Parents had mixed perceptions of the feedback form used in the study. Some felt it was very useful and filled it in prior to the face-to-face meeting, whereas others felt it was useful as a prompt of the kind of information that could be fed back/asked but did not want to fill the form in until there had been a face-to-face discussion.

\section{Timing and format of the plain English summary}

The plain English summary that was given to parents after the review to explain the answers to their questions, also provoked diverse reactions from parents. The majority of parents received the summary after the consultant follow-up meeting and some parents stated that they would have wanted this before, so they have more time to assimilate the information. Others felt having this information before the meeting would be detrimental, and it was acknowledged that this might vary on an individual basis. Some parents commented that they would want the option to ask and have answered different questions after all the results of the review were fed back.

\section{Enhanced patient safety—making pregnancy safer} Help improve future care

The majority of parents wished to be engaged in the review so they could ensure any lessons learnt were translated to improve care for the future. For example, many bereaved parents highlighted the need for improved antenatal education so they were more aware of some pregnancy and neonatal complications, such as cord prolapse and necrotising enterocolitis. Other parents highlighted issues such as lack of staffing in the neonatal care unit.

\section{Have clear method of communicating to parents how care has} changed or improved

Many parents stated that they would certainly appreciate more information fed back to them on how the reviews had enhanced patient safety. 
Table 2 Themes from bereaved parent's focus group postintervention

\begin{tabular}{lll} 
Themes & Subthemes & Quotes \\
\hline Better dialogue and & We could ask?! & "Overwhelmingly positive and beneficial process for people in a devastating position like us".
\end{tabular}

continuity of care

with parents

Parental engagement not "To be honest, I thought this (parent engagement in the PNMR) was standard".

part of routine care

"Even though it can never give you closure, as you said, we did still find it useful to be able to talk and make that comment?"

"I think the experience was really good, the experience of going through the study and having the opportunity to ask questions and not being judged by repeating the questions or not listening".

"It gave us a chance to actually voice our concerns, ask our questions, to actually ask the "why" question. Even though we couldn't get a definitive answer, at least being able to ask it is still helpful".

"And she did ask us about our care and we could use our voice again-we could explain the process that we went through and how we felt about certain things, so just by means of being able to share, in our opinion, that helped to"

"I think, if we had been somewhere else, in a different city and we'd not received this, I think we'd probably have had a very negative experience. I assumed this was a standard process, to be honest. I thought they was just following protocol, but I hadn't any experience before".

Face-to-face-useful to be "We found it useful for her (research midwife) to come into the home, into our own environment, in home environment so we didn't have to go anywhere. It was more relaxed and able to get a lot of things off our chest about different things that we felt could have been improved".

"There needs to be face-to-face discussion, at least one meeting face-to-face, where she (research midiwfe) gives us the opportunity to really think about what questions we want to ask to the consultant and what are the questions we want to ask to the professionals that review the case, and so we analyse that with her and I think, face-to-face, that's definitely best way to go forward".

Understand first-to move "I think I wouldn't be the person I am today. I'd be blaming everybody and I think l'd be quite an on angry person, because I just wouldn't know, but I know now and it's easier for me to deal with, that there was nothing that could be done".

'Cause we've still got questions we can't fully answer in our heads. So the whole process that you're talking about, I felt was really, really useful".

"I don't how I would have been if I couldn't have questions answered".

Improvements to the Right timing of providing perinatal mortality process

\section{feedback to the review}

"I think that was probably the best time (letting them know about the review in hospital). I think if we had left hospital, I think we probably wouldn't have been interested..."

"Personally, I think it was just about right. We had enough time to digest things. Still a trauma, but by that point we could talk about it. The letter was quite clear, so we could understand what you were asking us to do and we'd talk about it".

"I think I really appreciated the discussion on the following day, because I think any discussion on the day when ...... was born, I just don't remember at all what we were talking about".

"It was good, to have that distance as well, to see the things a bit in a different way, because on the week itself when that happened, we're just not ourselves, so that was a bit difficult. I know that I was keeping asking the same questions all the time, because my head was just not listening to anything".

Key contact in the hospital "To phone the hospital to speak to somebody to sort something out or to ask a question, it's was vital

Mixed perceptions of the feedback form impossible, because somebody's always busy, but...... is there as that in-between person. I didn't know that there was that sort of service available, maybe 'cause l've never been in this situation, but it is nice to have that sort of service rather than, 'Your baby's gone. That's it, go home and that's the end of it".

"She (research midwife) was just so helpful, because there was lots of questions. There was a lot of miscommunication as well, which she helped us sort out, because it's not so easy to contact people afterwards".

"Yeah. I looked at it and I didn't fill anything out, but it did get me thinking".

"It was really good that we prepared the questions. The template she gave us to complete before she came, I think that was good, to prepare ourselves to complete that questionnaire before, so we could get our head around the topics we wanted to talk to... And then, when we talked with her, there were maybe further questions coming along on top of that. I think that was good".

"I didn't fill the form out on my own. I did it with ........, and it's helpful, 'cause there was some of the questions was a bit over my head and she explained, and she (research midwife) said, 'Was that for you?' and I said no, and she was like, 'That's okay. We'll leave that'. I find it better going over it with her than trying to get my head round it on my own". 
Table 2 Continued

\begin{tabular}{ll}
\hline Themes & Subthemes \\
\hline & $\begin{array}{l}\text { Timing and format of the } \\
\text { plain English summary }\end{array}$
\end{tabular}

Quotes

"I think I would have liked that information from your meeting before we met with the consultant. To see roughly what happened and get our heads around it".

"I was quite nervous about the consultant appointment, thinking there might have been something else, or the fact of going to the hospital was really stressful, to go back to the hospital and things like that. So maybe getting that letter before about the option might be good, or at least that we can know, can have an indication if the analysis from the post-mortem shows new things or not".

\begin{tabular}{|c|c|c|}
\hline \multirow{4}{*}{$\begin{array}{l}\text { Enhanced patient } \\
\text { safety-making } \\
\text { pregnancy safer }\end{array}$} & \multirow[t]{3}{*}{ Help improve future care } & $\begin{array}{l}\text { "Yeah, to express it., just to get things off your chest and to be able to help other mums in the } \\
\text { future". }\end{array}$ \\
\hline & & $\begin{array}{l}\text { "Or to find out what kind of lessons have you learned from this that you've been able to implement } \\
\text { somewhere else in the hospital or somewhere in the NHS, that because of this review, you've } \\
\text { learned something. It'd be nice to get feedback to say all this..." }\end{array}$ \\
\hline & & $\begin{array}{l}\text { "I think having the support is crucial, but also having a voice to give your feedback on a process that } \\
\text { you have been through is also really powerful and it feels like you've been listened to. Nothing can } \\
\text { change the situation, but at least you think you might be able to help improve things in the future for } \\
\text { other people, and that's important". }\end{array}$ \\
\hline & $\begin{array}{l}\text { Have clear method of } \\
\text { communicating to parents } \\
\text { how care has changed or } \\
\text { improved }\end{array}$ & $\begin{array}{l}\text { "Even if... if it's personal, I can see that might not be logistic, but if not, even from a general point } \\
\text { of view, like have a link to an NHS website where... 'This review has helped by... we've learnt these } \\
\text { lessons from all the parents'”. }\end{array}$ \\
\hline
\end{tabular}

\section{HCP post-intervention focus group}

Four main themes emerged from the HCP postintervention focus group: continuity of care through the PNMR process, the positive and negative HCP perceptions of parent engagement; supporting HCP through the perinatal mortality process and improved information from reviews (table 3 , figure 1 ).

\section{Continuity of care through the PNMR process}

\section{Beneficial for meetings to have key independent contact}

HCP acknowledged the additional benefits for parents of continuity of care provided by the key contact and the value of the home visit as they perceived it allowed parents to process their grief and 'speak freely' about their experiences.

\section{Streamline meetings}

HCP perceived that parent feedback helped to facilitate the consultant follow-up meeting with the parents, allowing the consultant to be more prepared for the discussions.

The positive and negative HCP perceptions of parent engagement Positive

Overall HCP perceived that parent engagement in the PNMR was a positive improvement to clinical care. Staff

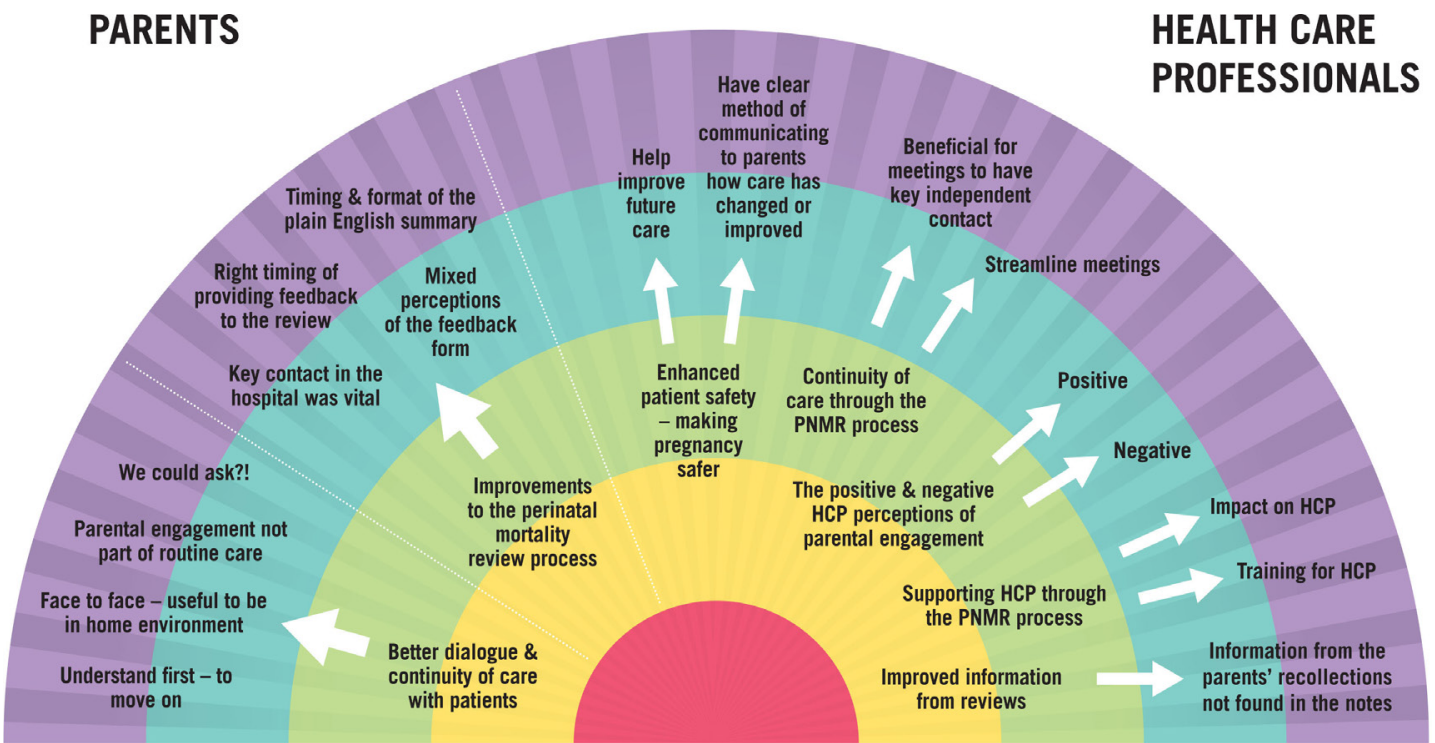

Figure 1 Findings from the parents and healthcare professionals (HCPs) focus groups post intervention. PNMR, perinatal mortality review. ${ }^{27}$ 
Table 3 Themes from healthcare professionals (HCPs) focus group postintervention

\begin{tabular}{|c|c|c|}
\hline Themes & Subthemes & Quotes \\
\hline \multirow[t]{2}{*}{$\begin{array}{l}\text { Continuity of care } \\
\text { through the PNMR } \\
\text { process }\end{array}$} & Streamline meetings & $\begin{array}{l}\text { 'When the key contact attended the follow-up meeting that also worked extremely well } \\
\text { to streamline and ensure the care and information was consistent and they had a familiar } \\
\text { face to meet with as coming back to hospital for the follow-up meeting is often traumatic } \\
\text { for parents'. }\end{array}$ \\
\hline & $\begin{array}{l}\text { Beneficial for } \\
\text { meetings to have } \\
\text { key independent } \\
\text { contact }\end{array}$ & $\begin{array}{l}\text { 'But I wonder whether that distancing (have an independent person) helps them to } \\
\text { be more honest, and maybe getting more out of it when its somebody not directly } \\
\text { involved, and it's really easier for someone to raise their grievances and their questions } \\
\text { and stuff with somebody. Because I think despite anger, it's very easy for us to forget } \\
\text { the imbalance in the relationship between ourselves as people that have cared for their } \\
\text { child, and how difficult it is sometimes to say, 'I don't know why that happened', or, 'I } \\
\text { don't know, why did they do that?' and I think that may be easier if you don't seemingly } \\
\text { represent the team because you weren't associated with them at the time'. }\end{array}$ \\
\hline
\end{tabular}

The positive and Positive negative HCP perceptions of parental engagement

'It really streamlined the meeting as you knew what was important to the parents so you could usually be extremely well prepared for what they wished to discuss and have already discussed this at length in the PMRT. One example was that a couple had many technical questions about the post mortem report so I invited our pathologist to attend a follow-up meeting and that was a success and appreciated by the couple as they were able to ask him questions and get the clinical detail at the same time'.

'I think the information has been really valuable for us as clinicians, we can get quite carbon-clinical about how and why the baby died, or whatever, but lack the humanity of it, and I think that this (parent engagement) has affected the way our conversations have gone, in a positive way. Sometimes we can be quite short and cutting about it, and dismissive...'

'I think it makes the meeting have a more sense of more purpose. I know how important it is, I recognise it's a very valuable exercise, but somehow by bringing in like you say, the family element of it, and this is what they want to know, and this is what they're wondering, helps like you say'.

'It's made the meeting more well-rounded, I think its been a good way to focus discussion, and looking at what they're concerned about, and what we do say a lot of time is, nothing can be changed, or nothing could have affected it. But I think to recognise what they're concerned about, it's important.'

'It really focussed the meeting on discussing what was important to the parents, which is not always what the healthcare professional would perceive is important to discuss'.

Negative

'I do think it makes meetings much longer which obviously is a resource thing and we must consider, and we're not able to always get through all the cases that we want to get through, just because of time pressures'.

Supporting HCP through the PNMR process
Impact on HCP

'I'm thinking if you've been to see a parent, and then you link in with the professionals that are involved in that parent, and we filter out the key learning points at a higher level, refine it a little bit. But there again have an opportunity to document all these other issues that can be dealt with. I think to bring it all to a group where everybody can learn'.

'Participant 1: I know there were a couple of members of staff that didn't want to attend the meeting of their case that was going to be discussed, because they felt they were too upset to attend it.

Participant 2: And again, the pre-meet might be just a one-on-one with them.

Participant 3: Yes, that's what l'm saying about these things coming out in a big group, sometimes that's not appropriate'.

Training for HCP
'I think there is an issue of safeguarding, [Research midwife] is going out (to do home visit) to unknown people. I mean we do screen them to a degree but, those emotions that go around after something like that's happened, and here's a representative from the hospital knocking on their door, when they are really angry at the Trust whether its justified or not, is an issue that we need to take forward as well'.

'I think recognised that we need more counselling staff, particularly in the cases of when there have been allegations that people haven't done... like the community midwife, that community midwife was absolutely mortified. To be the centre of somebody's anger is really very difficult when you have tried your hardest'.

'Also, its supporting staff through allegations of miss-care or whatever, when its thrown out of sheer anger of the situation'. 
Table 3 Continued

\begin{tabular}{lll}
\hline Themes & Subthemes & Quotes \\
\hline & $\begin{array}{l}\text { 'I think we have to be very careful about trainees and junior people, and even our Band } 7 \\
\text { nurses that are going, that this is channelled in a positive way, which is why it has to be } \\
\text { managed at quite a senior level'. } \\
\text { 'I think we're not doing the parents that we serve any favours by losing our quality staff } \\
\text { managing this inappropriately in the long-term'. }\end{array}$ \\
$\begin{array}{lll}\text { Improved information } \\
\text { from reviews }\end{array}$ & $\begin{array}{l}\text { Information from } \\
\text { the parents' } \\
\text { recollections not definitely identified issues that we just could not get from reading the notes, some } \\
\text { found in the notes } \\
\text { examples were itching (raised bile acids, but itching not documented in the notes), } \\
\text { staffing issues on NICU, symptoms of PET headache/swollen legs not in notes (PET/ } \\
\text { abruption) and attitudes of staff stopping them coming into DAU'. } \\
\text { 'Details and information emerged which wasn't clear from the medical notes which made } \\
\text { it more individualised to the parents which could help them in a future pregnancy'. }\end{array}$ \\
\hline
\end{tabular}

perceived that parent engagement allowed for a more 'wellrounded' discussion and 'focused' the perinatal mortality review meeting, giving it a greater 'sense of purpose'. It was also stated that parent involvement brought about a greater degree of 'humanity' to the PNMR meetings that staff felt was previously lacking in the more 'carbon-clinical' and less patient focused PNMR meetings.

\section{Negative}

There were, however, some negative perceptions of parent engagement, including distress some HCP experienced on receipt of the parents' feedback. Difficulties for HCP also arose where there was conflict in the parents' perception of events compared with documentation of events in the case records. HCP reported that parent feedback led to additional time and resources required to discuss each case within the meeting.

\section{Supporting HCP through the PNMR process Impact on HCP and training}

Supporting HCP through the perinatal mortality review process was recognised as extremely important to staff. Training and counselling were deemed crucial by participants to support staff, especially when there have been instances of negative feedback of care.

\section{Improved information from reviews}

Information from the parents' recollections not found in the notes

HCP perceived that, details and information emerged from the parent feedback, which was not clear from the medical case notes, for example, parents' describing itching that was not documented in the notes led to a diagnosis of obstetric cholestasis, and changes to staffing in the neonatal unit were reported to have stemmed directly from parent feedback. It was also important for HCP that action plans were made and followed through as it was pointless asking them (parents) and ignoring or not actioning' their feedback. Overall, HCP noted that parents' feedback led to a more in-depth understanding of events, of potential causation of the perinatal death and, in some cases, these additional insights were used by HCP to guide counselling for a future pregnancy.
Parent comments in the feedback form and recommendations Emergent themes from parent comments on their feedback forms in order of frequency are described in online supplemental file 4 .

\section{DISCUSSION}

Overall, this study showed parental engagement in the PNMR process is beneficial in terms of parents being able to ask questions, being heard, processing their grief and being able to understand why their baby has died. Furthermore, it confirms the importance of continuity of care in this context, as this was an overlapping theme in both focus groups.

HCP found that parent's involvement focused and improved the PNMR meetings, and follow-up consultations. Our findings suggest that engaging parents improved the review process by highlighting issues (good or bad) not found in the medical notes, and was important for identifying the cause of death, or for resolving care and system delivery problems in the maternity unit. This suggests that engaging parents in the review process after the death of a baby is invaluable to parents, and critically it can improve patient safety lessons learnt from the reviews.

\section{Strengths and limitations}

This study is limited by being carried out in a single maternity unit in the UK. This will impact the findings in two ways: first, each maternity unit may have different processes for undertaking reviews after the death of a baby, and second, the demographics of the population being homogeneous, with limited participation from women from black and minority ethnic groups and most women living within reasonably short distance from the maternity unit. There is also likely selection bias of participants who were willing to take part in the study being those most likely to engage with healthcare services.

Strengths of our study include the robust development of our intervention after extensive preliminary work including parents/patients, national experts and stakeholders and charities. Moreover, to our knowledge this is 
the first study to formally investigate parental engagement in the review process after the death of a baby. The new national PMRT in the UK aims to improve the consistency of how PNMR are undertaken in each maternity unit and seeks parental involvement in the process. We developed our study working closely with the MBRRACE-UK/PMRT collaboration to ensure recommendations will be applicable across the UK.

\section{Interpretation}

The 2016 Better Births report of the National Maternity Review set out a strong recommendation that there should be continuity of care to ensure safe care based on a relationship of mutual trust and respect in line with each woman's decisions. ${ }^{18-23}$ Our study provides evidence for the importance of continuity of care and optimal timing of contacts after perinatal bereavement, which was valued highly by the parents in our study. The value parents attached to this and the face-to-face nature of the discussions to obtain questions for the PNMR process, indicates that to function optimally, parent involvement in the PNMR process requires skilled human resource. Communication by letter to obtain parent's questions is less likely to yield useful information for both parents and professionals.

A survey of views of bereaved multiple-birth parents on discussions surrounding death found that parents reported clear, careful explanations with written summaries, and the time to ask questions during decisionmaking after a baby's death were extremely helpful. ${ }^{24}$ This is similarly reflected in the perception of parents in our study. A qualitative study of parents' perceptions of the child death review process concluded that for many parents not knowing why their baby died may cause further distress and having as much information as possible could help parents to emotionally accept and make sense of the death to themselves. ${ }^{25}$ This supports our findings that further knowledge and engagement in the PNMR can facilitate understand and coping mechanisms in the grief processes. Furthermore, a study undertaken in a district in France described experiences including interviews with bereaved women in a clinical perinatal mortality audit. They demonstrated that involving parents in perinatal audit is feasible, provides valuable information and can have benefits for the women themselves. ${ }^{26}$

The first PMRT annual report was published in 2019. ${ }^{14}$ Overlapping or similar themes that emerged in the first PMRT report describing parent's feedback were: why, guilt, distrust of the system, antenatal care and the future. In contrast to our study findings, the first PMRT review found that $42 \%$ of parents had no concerns about their care. ${ }^{14}$ The authors have, however, concluded that this may to some extent reflect the poor quality of parent engagement. Our findings have demonstrated that having a key contact were vital to the success of the process. Furthermore, we have highlighted the need to ensure HCP are fully supported through the process and any feedback is actioned in an appropriate and sensitive manner. Moreover, psychologist support has been shown to be beneficial for both parents and staff ${ }^{26}$ and should be available for all. These measures undoubtedly need resources to implement and therefore, to meaningfully engage with parents, hospitals need to provide adequate staffing and time for the process. The process, similar to other safety initiatives in maternity care with the aim of reducing the perinatal death rate, will indeed not be successful unless it is seen as a priority and given the necessary stakeholder support from government, commissioning bodies, trusts and local departments.

Our portfolio of PARENTS studies and the focus groups findings from this study have identified interventions or practical recommendations to support parent engagement in PNMRs (online supplemental file 5).

Future research should focus on consideration of barriers to parent engagement in different countries and settings, the 'quality' and timing of parental engagement and also further assessment of long-term impacts on parents' well-being and safety culture in maternity care.

\section{CONCLUSION}

With sufficient resources, parental engagement in the PNMR is achievable and vital to improving future care in maternity, with little harm. It is useful and empowering for parents and HCP alike, including informing discussions of causation. All hospitals should support bereaved parents so that they can take up the option to engage with the review of their baby's death.

\section{Author affiliations}

${ }^{1}$ Bristol Medical School, Department of Translational Health Sciences, University of Bristol, Faculty of Health Sciences, Bristol, UK

${ }^{2}$ Maternal and Fetal Health Research Centre, University of Manchester, Manchester, UK

${ }^{3}$ SANDS, London, UK

${ }^{4}$ International Stillbirth Alliance, Bristol, UK

${ }^{5}$ National Perinatal Epidemiology Unit, University of Oxford, Oxford, UK

${ }^{6}$ University College London Institute for Women's Health, London, UK

${ }^{7}$ University College London Hospital, London, UK

${ }^{8}$ Wellcome EPSRC centre for Interventional + Surgical Sciences (WEISS), London, UK

${ }^{9} \mathrm{NIHR}$ UCLH Biomedical Research Centre, London, UK

Twitter Alexander Edward Heazell @MCR_SB_Research

Acknowledgements The authors would like to thank all the parents and healthcare professional who took the time to participate and advise on the study.

Contributors All authors meet the ICMJE criteria for authorship. CBu, CBe, $\mathrm{CS}, \mathrm{DB}, \mathrm{DS}$ and AEH conceived the study idea, and were involved in the study design, conduct and analysis. LT was involved in study design and conduct. ML was involved in study conduct and analysis. JK was involved in study design and conduct. All authors were involved in preparation and writing of the manuscript.

Funding This work was supported by The Health Foundation, UK, grant number 7700 .

Competing interests Authors include the chair and members of the national Perinatal Mortality Review Tool (PMRT) group.

Patient consent for publication Not required. 
Ethics approval Approvals were obtained from the Health Research Authority (Ref 17/WM/0123).

Provenance and peer review Not commissioned; externally peer reviewed. Data availability statement No data are available.

Supplemental material This content has been supplied by the author(s). It has not been vetted by BMJ Publishing Group Limited (BMJ) and may not have been peer-reviewed. Any opinions or recommendations discussed are solely those of the author(s) and are not endorsed by BMJ. BMJ disclaims all liability and responsibility arising from any reliance placed on the content. Where the content includes any translated material, BMJ does not warrant the accuracy and reliability of the translations (including but not limited to local regulations, clinical guidelines, terminology, drug names and drug dosages), and is not responsible for any error and/or omissions arising from translation and adaptation or otherwise.

Open access This is an open access article distributed in accordance with the Creative Commons Attribution Non Commercial (CC BY-NC 4.0) license, which permits others to distribute, remix, adapt, build upon this work non-commercially, and license their derivative works on different terms, provided the original work is properly cited, appropriate credit is given, any changes made indicated, and the use is non-commercial. See: http://creativecommons.org/licenses/by-nc/4.0/.

ORCID iDs

Christy Burden http://orcid.org/0000-0001-6409-5238

Alexander Edward Heazell http://orcid.org/0000-0002-4303-7845

Dimitrios Siassakos http://orcid.org/0000-0002-1078-9856

\section{REFERENCES}

1 CQC care quality commission. Available: https://www.cqc.org.uk/ category/keywords/maternity [Accessed 29 Mar 2020].

2 Kirkup B. The report of the morecambe bay investigation [online]. Available: https://www.gov.uk/government/uploads/system/ uploads/ attachment_data/file/408480/47487_MBI_Accessible_v0.1.pdf [Accessed 19 Jun 2020]

3 Robert Francis. The mid staffordshire NHS foundation trust public inquiry, 2013. Available: http://webarchive.national archives.gov.uk/ 20140407084003/http://www.midstaffspublicinquiry.com/ [Accessed 5 Feb 2017].

4 Boyle FM, Horey D, Siassakos D, et al. Parent engagement in perinatal mortality reviews: an online survey of clinicians from six high-income countries. BJOG 2021;128:696-703.

5 Draper ES, Kurinczuk JJ, Kenyon S, eds. MBRRACE-UK 2017 Perinatal confidential enquiry: term, singleton, intrapartum stillbirth and intrapartum-related neonatal death. Leicester: The Infant Mortality and Morbidity Studies, Department of Health Sciences, University of Leicester, 2017.

6 NHS England. National guidance on learning from deaths, 2017. Available: https://www.england.nhs.uk/wp-content/uploads/2017/03/ nqb-national-guidance-learning-from-deaths.pdf [Accessed 24 Jul 2020].

7 Bakhbakhi D, Siassakos D, Burden C, et al. Learning from deaths: parents' active role and engagement in the review of their Stillbirth/ perinatal death (the parents 1 study). BMC Pregnancy Childbirth 2017; 17:333.

8 Stroebe M, Schut $\mathrm{H}$. The dual process model of coping with bereavement: rationale and description. Death Stud 1999;23:197-224.
9 Heazell AEP, Siassakos D, Blencowe $\mathrm{H}$, et al. Stillbirths: economic and psychosocial consequences. Lancet 2016;387:604-16.

10 Burden C, Bradley S, Storey C, et al. From grief, guilt pain and stigma to hope and pride - a systematic review and meta-analysis of mixed-method research of the psychosocial impact of stillbirth. BMC Pregnancy Childbirth 2016;16:9.

11 Campbell HE, Kurinczuk JJ, Heazell A, et al. Healthcare and wider societal implications of stillbirth: a population-based cost-of-illness study. BJOG 2018;125:108-17.

12 Bakhbakhi D, Burden C, Storey C, et al. PARENTS 2 Study: a qualitative study of the views of healthcare professionals and stakeholders on parental engagement in the perinatal mortality review-from 'bottom of the pile' to joint learning. BMJ Open 2019;8:8-11.

13 Bakhbakhi D, Siassakos D, Lynch M, et al. Parents 2 study: consensus report for parental engagement in the perinatal mortality review process. Ultrasound Obstet Gynecol 2019;54:215-24.

14 Chepkin S, Prince S, Johnston T. Learning from standardised reviews when babies die. National perinatal mortality review tool: first annual report. Oxford: National Perinatal Epidemiology Unit, 2019. https:// www.npeu.ox.ac.uk/pmrt/reports

15 Bakhbakhi D, Siassakos D, Storey C, et al. PARENTS 2 study protocol: pilot of parents' active role and engagement in the review of their stillbirth/perinatal death. BMJ Open 2018;8:8.

16 Consolidated criteria for reporting qualitative research (COREQ); a 32 item checklist for interviews and focus groups. Available: https:// www.equator-network.org/reporting-guidelines/coreq/ [Accessed 01 Sep 2020].

17 Braun V, Clarke V. Using thematic analysis in psychology. Qual Res Psychol 2006;3:77-101.

18 Implementing better births: continuity of carer, 2017. Available: https://www.england.nhs.uk/wp-content/uploads/2017/12/ implementing-better-births.pdf [Accessed 18 May 2020].

19 Better births: improving outcomes of maternity services in England: a five year forward view for maternity care https://www.england.nhs. uk/mat-transformation/implementing-better-births/mat-review/

20 Rayment-Jones H, Murrells T, Sandall J. An investigation of the relationship between the caseload model of midwifery for socially disadvantaged women and childbirth outcomes using routine data-a retrospective, observational study. Midwifery 2015;31:409-17.

21 Sandall J, Soltani H, Gates S, et al. Midwife-led continuity models versus other models of care for childbearing women. Cochrane Database Syst Rev 2016;4:CD004667.

22 Walsh D, Devane D. A metasynthesis of midwife-led care. Qual Health Res 2012;22:897-910.

23 Pector EA. Views of bereaved multiple-birth parents on life support decisions, the dying process, and discussions surrounding death. $J$ Perinatol 2004;24:4-10.

24 Garstang J, Griffiths F, Sidebotham P. What do bereaved parents want from professionals after the sudden death of their child: a systematic review of the literature. BMC Pediatr 2014;14:269.

25 Garstang J, Griffiths F, Sidebotham P. Rigour and rapport: a qualitative study of parents' and professionals' experiences of joint agency infant death investigation. BMC Pediatr 2017;17:48.

26 Sauvegrain P, Zeitlin J. Investigating the benefits and challenges of including bereaved women in research: a multifaceted perinatal audit in a socially disadvantaged French district. BMJ Open 2020;10:e034715.

27 Dahlgren G, Whitehead M. Policies and Strategiesto promote social equity in health. Stockholm, Swedeb: Insitute for Future Studies, 1991. 